\title{
Germinação de sementes de Barbacenia paranaensis (VelloziaceaE)
}

Luciele Milani Zem ${ }^{1 *}$, Alex Caetano Pimenta ${ }^{2}$, Katia Christina Zuffellato-Ribas ${ }^{3}$

e Henrique Soares. Koehler ${ }^{4}$

${ }^{1}$ Universidade Federal do Paraná - UFPR, Departamento de Fitotecnia e Fitossanitarismo, Rua dos Funcionários, 1540,

Curitiba, PR, Cep: 81531-990, Brasil. E-mail: luzem@uol.com.br

${ }^{2}$ Instituto Federal de Educaçá, Ciência e Tecnologia de do Mato Grosso, Campus São Vicente, BR 364 Km 329,

São Vicente da Serra, Santo Antônio do Leverger, MT, Brasil, Cep: 78106-960. E-mail: profpimenta@hotmail.com

${ }^{3}$ Universidade Federal do Paraná - UFPR, Departamento de Botânica, Caixa Postal 19031, Curitiba, PR, Brasil,

Cep: 81531-970, Brasil. E-mail: kazu@ufpr.br

${ }^{4}$ Universidade Federal do Paraná - UFPR, Departamento de Fitotecnia e Fitossanitarismo, Rua dos Funcionários, 1540,

Curitiba, PR, Cep: 81531-990, Brasil. E-mail: koehler@ufpr.br

* Autor correspondente: Departamento de Fitotecnia e Fitossanitarismo. Universidade Federal do Paraná (UFPR). Rua

Quintino Bocaiuva, 105. Bairro Cabral, Curitiba, PR, CEP: 80.035-090. Fax: (41-3353-5384)

ISSN 2448-0479

Resumo - Barbacenia paranaensis é uma espécie da família Velloziaceae que ocorre no Estado do Paraná, de hábito rupícola e saxícola, incluída na lista de plantas raras do Brasil. Possui sementes pequenas, as quais necessitam de alguns padrôes para que a germinação ocorra, tais como luz e temperaturas. Assim, objetivando avaliar a germinação de suas sementes foram elaborados tratamentos com quatro diferentes temperaturas $\left(20^{\circ} \mathrm{C}, 25^{\circ} \mathrm{C}, 30^{\circ} \mathrm{C}\right.$ e $\left.20-30^{\circ} \mathrm{C}\right)$ em duas condições de luz (luz constante e ausência de luz), analisados num delineamento inteiramente casualizado em arranjo fatorial (4x2) com quatro repetições de 25 sementes cada. Foram consideradas as variáveis primeira contagem de germinaçấo, germinação final e índice de velocidade de germinação, sendo possível concluir que a temperature ótima para germinação das sementes de Barbacenia paranaensis está na faixa de $25^{\circ} \mathrm{C}$ e $30^{\circ} \mathrm{C}$.

Palavras-chave - Luz. Escuro. Temperatura. Fotoblastismo.

Abstract - Barbacenia paranaensis is a species of Velloziaceae family that occurs in the State of Paraná, on the list of rare plants in Brazil, rupicolous and saxicolous habit. Its seeds are small, with your affected germination behavior, a fact that demand well defined patterns for germination occurs, among which photoblastism and specific temperatures. The objective was to evaluate the germination of their seeds at different temperatures with the presence and absence of light. The treatments consisted of four different temperatures $\left(20^{\circ} \mathrm{C}, 25^{\circ} \mathrm{C}, 30^{\circ} \mathrm{C}\right.$ and $\left.20-30^{\circ} \mathrm{C}\right)$ in two light conditions (constant light and the dark), using a completely randomized design in a factorial arrangement $(4 \times 2)$ with four replicates of 25 seeds each. The following variables were analyzed: first cou$\mathrm{nt}$, final germination and germination speed index. It is possible to concluded that the optimum temperature for germination of Barbacenia paranaensis seeds is in the range of $25^{\circ} \mathrm{C}$ and $30^{\circ} \mathrm{C}$.

Keywords - Light. Dark. Temperature. Photoblastim.

Recebido em: 04 de outubro de 2016.

Aprovado em: 20 de dezembro de 2016.

\section{INTRODUÇÁO}

O gênero Barbacenia possui cerca de 100 espécies, com distribuiçấo pela América Central, Venezuela, Planalto Central brasileiro e pelo Estado do Paraná (MELLO-SILVA, 2004), sendo Barbacenia paranaensis L. B. Sm uma das representantes da família Velloziaceae que ocorre no Estado do Paraná (MELLO-SILVA, 2013). A espécie está incluída na lista de plantas raras do Brasil e é pouco estudada, com grande carência de informaçóes a seu respeito (MELLO-SILVA, 2009).

Barbacenia paranaensis apresenta hábito rupícola e saxícola, estabelecendo-se em paredóes secos, rochosos e com baixa densidade de plantas ao seu redor, 
dificilmente sendo encontrada em solos horizontais (LUZ, 2014). A espécie possui floraçáo com características típicas da família Velloziaceae (SAZIMA, 1978), com pico de florescimento ocorrendo apenas uma vez ao ano, durante os meses mais quentes e chuvosos (LUZ, 2014).

Suas sementes são pequenas, com cerca de três $\mathrm{mm}$ de comprimento e barocóricas, com dispersão por gravidade devido à posição pendente de seus frutos em paredóes rochosos (LUZ, 2014). O tamanho reduzido das sementes de $B$. paranaensis pode afetar aspectos ecológicos da espécie, incluindo aqueles que possuem relação direta com seu comportamento germinativo (LEISHMANN et al., 2000; MOLES et al., 2005), pois são sementes exigentes quanto às condiçóes ambientais para a germinação, incluindo fotoblastismo e temperaturas específicas (GRIME et al., 1981).

Luz e temperatura são considerados fatores ambientais importantes no controle da germinação e a sua interação influencia diretamente no estabelecimento das plântulas (BASKIN; BASKIN, 1988; GHERSA; BENETH-ARNOLD; MARTINEZ-GHERSA, 1992). Em geral a luz é necessária para a germinação de sementes pequenas (BEWLEY; BLACK, 1994), como é o caso da $B$. paranaensis. A temperatura, por sua vez, pode influenciar na velocidade e na porcentagem de germinação, uma vez que cada espécie apresenta uma temperatura mínima, máxima e ótima para a germinação de suas sementes (BEWLEY; BLACK, 1994; MARCOS-FILHO, 2005).

Sendo assim, com o presente trabalho se objetivou avaliar a germinação de sementes de Barbacenia paranaensis em diferentes temperaturas na presença e ausência de luz, bem como avaliar o índice de velocidade de germinação.

\section{MATERIAIS E MÉTODOS/METODOLOGIA}

A pesquisa foi conduzida no Laboratório de Análise de Sementes do Departamento de Fitotecnia e Fitossanitarismo da Universidade Federal do Paraná, em Curitiba-PR, no período de maio a junho de 2014. Foram utilizadas sementes de B. paranaensis, provenientes da localidade denominada Salto Santa Rosa, no município de Tibagi - PR. As sementes foram acondicionadas em sacos de papel Kraft e armazenadas em ambiente controlado, com temperatura de $18^{\circ} \mathrm{C}$ e $50 \%$ de Umidade Relativa do ar. antes da instalaçâo do experimento.

\subsection{Teste de germinação}

As sementes foram distribuídas sobre papel mata-borrão, acondicionado em caixas plásticas tipo gerbox transparentes $(11,0 \times 11,0 \times 3,5 \mathrm{~cm})$, sobre quarto folhas de papel filtro $6,5 \mathrm{~g}$, umedecido com água em quantidade equivalente a 2,5 vezes a massa do substrato seco, mantidas em germinador, sendo combinados os fatores temperatura e luz. As sementes foram incubadas a $20^{\circ} \mathrm{C}, 25^{\circ} \mathrm{C}, 30^{\circ} \mathrm{C}$ e 20 - $30^{\circ} \mathrm{C}$ sob luz branca constante em germinadores tipo Mangelsdorf e B.O.D. (Biochemical Oxigen Demand), bem como na ausência de luz por meio do uso de caixas plásticas tipo gerbox envoltas com papel alumínio. A luz branca foi fornecida por meio de lâmpadas fluorescentes existentes na porta dos germinadores e a temperatura de cada germinador era mantida por sensores previamente calibrados para cada temperatura do estudo. A umidade do material foi mantida com o uso de borrifadores de água no momento da avaliação diária, sempre que necessário. Vale ressaltar que o experimento conduzido no escuro recebeu uma incidência de luz no momento da avaliação diária. $\mathrm{Na}$ avaliação do teste de germinação utilizou-se como critério as Regras para Análise de Sementes (BRASIL, 2009).

\subsection{Primeira contagem de germinaçáo}

Determinada a partir de avaliações diárias do teste de germinaçấo, considerando como primeira contagem o dia em que houve o pico máximo da incidência de sementes germinadas, segundo o critério plântula normal estabelecido nas Regras para Análise de Sementes (BRASIL, 2009).

\section{3 Índice de Velocidade de Germinação (IVG)}

Conduzido em conjunto com o teste de germinação, realizando-se avaliaçóes das plântulas diariamente, a partir do surgimento das primeiras plântulas normais, sendo a contagem final estabelecida pelo momento em que a incidência de plântulas se encerrou. O IVG foi calculado pela fórmula proposta por Maguire (1962).

Os tratamentos foram constituídos por quatro diferentes temperaturas $\left(20^{\circ} \mathrm{C}, 25^{\circ} \mathrm{C}, 30^{\circ} \mathrm{C}\right.$ e 20 $30^{\circ} \mathrm{C}$ ) em duas condiçóes de luz (luz constante e ausência de luz). Os dados obtidos em cada teste foram analisados de acordo com um delineamento inteiramente casualizado, em arranjo fatorial ( 4 x 2) composto por oito tratamentos com quatro repetiçóes de 25 sementes cada. 
A homogeneidade das variâncias dos tratamentos, para cada uma das variáveis estudadas, foi verificada pelo teste de Bartlett e para as variáveis cujas variâncias foram homogêneas aplicou-se análise de variância e o teste de Tukey ao nível de 5\% de significância para comparação de médias.

\section{RESULTADOS E DISCUSSÃO}

Pela análise de variância percebeu-se interação entre as fontes de variaçáo (luz e temperatura) para todas as variáveis estudadas, demonstrando que estas são dependentes. Considerando-se os fatores isoladamente, houve diferença significativa ao nível de 1\% de probabilidade para primeira contagem e índice de velocidade de germinação, não havendo diferença significativa para a porcentagem de germinação.

A primeira contagem de germinaçáo ocorreu no $11^{\circ}$ dia após a semeadura, quando foram constatados $59 \%$ e $61 \%$ de germinação, respectivamente com as temperaturas de $25^{\circ} \mathrm{C}$ e $30^{\circ} \mathrm{C}$ e na presença de luz, sem que houvesse diferenças estatísticas entre eles, que foram superiores aos resultados observados com as temperaturas de $20{ }^{\circ} \mathrm{C}$ e $20-30{ }^{\circ} \mathrm{C}$, onde não se observou germinação (Tabela 1). $\mathrm{Na}$ ausência de luz só germinaram aquelas sementes submetidas à $30^{\circ} \mathrm{C}$ (Tabela 1).

Tabela 1 - Médias obtidas para primeira contagem de germinação em sementes de Barbacenia paranaensis L. B. Sm., na presença (P) e ausência (A) de luz, Curitiba-PR, 2014.

\begin{tabular}{cccccc}
\hline \multicolumn{5}{c}{ Temperatura } \\
\hline Luz & $20^{\circ} \mathrm{C}$ & $25^{\circ} \mathrm{C}$ & $30^{\circ} \mathrm{C}$ & $20-30^{\circ} \mathrm{C}$ & Média \\
\hline $\mathrm{P}$ & $0,0 \mathrm{aB}$ & $59,0 \mathrm{aA}$ & $61,0 \mathrm{aA}$ & $0,0 \mathrm{aB}$ & $30,0 \mathrm{a}$ \\
$\mathrm{A}$ & $0,0 \mathrm{aB}$ & $0,0 \mathrm{bB}$ & $37,0 \mathrm{bA}$ & $0,0 \mathrm{aB}$ & $9,0 \mathrm{~b}$ \\
\hline Média & $0,0 \mathrm{C}$ & $29,0 \mathrm{~B}$ & $49,0 \mathrm{~A}$ & $0,0 \mathrm{C}$ & \\
\hline
\end{tabular}

Médias seguidas de mesma letra minúscula na coluna e maiúscula na linha não diferem estatisticamente entre si pelo teste de Tukey ao nível de $5 \%$ de significância.

Os resultados apresentados mostram que as interaçóes dos fatores físicos do ambiente, como temperatura e luz, podem influenciar no estabelecimento de plântulas (BASKIN; BASKIN, 1988; GHERSA; BENETH-ARNOLD; MARTINEZ-GHERSA, 1992), uma vez que existe uma amplitude desses fatores na qual as sementes podem germinar (BEWLEY; BLACK, 1994; SMITH, 1975). Cada espécie possui limites de temperatura mínima, ótima e máxima, sendo que a temperatura ótima propicia a máxima porcentagem de germinação em menor tempo, en- quanto que sob as temperaturas mínima ou máxima há baixo índice de germinação (BEWLEY; BLACK, 1994; MARCOS-FILHO, 2005).

Em muitas espécies a presença de luz favorece a germinação das sementes, como foi o caso da $B$. paranaensis, dando a entender que, em um primeiro momento ela poderia ser considerada fotoblástica positiva. No entanto, ao avaliar os resultados, notou-se que nas temperaturas de $20^{\circ} \mathrm{C}$ e $20-30^{\circ} \mathrm{C}$ (Tabela 1) não houve a interferência da luz na primeira contagem de germinação, permitindo inferir que $B$. paranaenses é indiferente quanto ao fotoblastismo, porém por receber uma pequena quantidade de luz no momento da avaliação, fica a dúvida da afirmação se a luz pode ter interferido neste resultado.

O experimento foi encerrado 24 dias após sua implantação, sendo constatado que a porcentagem de germinação de sementes de $B$. paranaensis, na presença de luz, não apresentou diferença significativa para todas as temperaturas analisadas, diferentemente do observado em primeira contagem. Já na ausência de luz, a temperatura de $20-30^{\circ} \mathrm{C}(97,00 \%)$ diferiu estatisticamente apenas da temperatura de $20^{\circ} \mathrm{C}$ $(82,00 \%)$ (Tabela 2).

Tabela 2 - Médias obtidas para porcentagem de germinação em sementes de Barbacenia paranaensis L. B. Sm., na presença (P) e ausência (A) de luz, Curitiba-PR, 2014.

\begin{tabular}{|c|c|c|c|c|c|}
\hline \multicolumn{6}{|c|}{ Temperatura } \\
\hline Luz & $20^{\circ} \mathrm{C}$ & $25^{\circ} \mathrm{C}$ & $30^{\circ} \mathrm{C}$ & $20-30^{\circ} \mathrm{C}$ & Média \\
\hline $\mathrm{P}$ & $93,0 \mathrm{aA}$ & $85,0 \mathrm{aA}$ & $91,0 \mathrm{aA}$ & $80,0 \mathrm{bA}$ & $87,0 \mathrm{a}$ \\
\hline A & $82,0 \mathrm{bB}$ & $94,0 \mathrm{aAB}$ & $90,0 \mathrm{aAB}$ & $97,0 \mathrm{aA}$ & $91,0 \mathrm{a}$ \\
\hline Média & $88,0 \mathrm{~A}$ & $90,0 \mathrm{~A}$ & $91,0 \mathrm{~A}$ & $89,0 \mathrm{~A}$ & \\
\hline
\end{tabular}

Médias seguidas de mesma letra minúscula na coluna e maiúscula na linha não diferem estatisticamente entre si pelo teste de Tukey ao nível de $5 \%$ de significância.

Ao analisar a germinação ocorrida nas diferentes temperaturas quanto à presença ou ausência de luz, apenas as temperaturas de $20^{\circ} \mathrm{C}$ e $20-30^{\circ} \mathrm{C}$ diferiram estatisticamente entre si, enquanto que as demais não apresentaram diferença significativa (Tabela 2). $\mathrm{Na}$ temperatura de $20^{\circ} \mathrm{C}$ observou-se maior porcentagem de germinação na presença de luz $(93,00 \%)$, enquanto que na alternância de temperatura (20$30^{\circ} \mathrm{C}$ ) a maior porcentagem de germinação foi observada na ausência de luz (97,00\%) (Tabela 2). Essa condição permite abrir uma discussão sobre o fotoblastismo das sementes de $B$. paranaensis uma vez que poderiam ser consideradas fotoblásticas positivas bem como indiferentes, uma vez que a luz 
pode ter interferido no processo germinativo de suas sementes no momento em que foram realizadas as avaliaçôes diárias, sendo com isso necessário realizar novos experimentos com delineamentos específicos para este tipo de avaliaçáo.

Garcia e Diniz (2003), estudaram o comportamento germinativo de três espécies da família Velloziaceae e as caracterizaram-nas como fotoblásticas positivas, visto que a luz interferiu no processo germinativo. Já Soares e Garcia (2007), ao realizarem testes germinativos de sementes de Vellozia graminea, também da família Velloziaceae, possibilitou classifica-la como fotoblásticas neutras.

Com relaçáo à temperatura de germinaçáo, B. paranaensis é semelhante à Vellozia leptopetala (Velloziaceae), visto que sua germinabilidade foi alta e estatisticamente semelhante, na faixa de $20^{\circ} \mathrm{C}$ a $30^{\circ} \mathrm{C}$, na presença da luz (GARCIA; JACOBI; RIBEIRO, 2007). Este amplo intervalo de temperaturas observado para a germinação de $B$. paranaensis propicia alta capacidade de estabelecimento da espécie em campo, aumentando suas possibilidades de sobrevivência e competição em relação àquelas que germinam em faixas mais restritas de temperatura (SOARES; GARCIA, 2007).

De modo geral, as altas porcentagens de germinação em faixas amplas de temperaturas observadas em sementes de $B$. paranaensis $\left(20^{\circ} \mathrm{C}, 25^{\circ} \mathrm{C}, 30^{\circ} \mathrm{C}\right.$ e $20^{\circ}-30^{\circ} \mathrm{C}$ ) (Tabela 2) e de outras espécies da família Velloziaceae $\left(25^{\circ} \mathrm{C}\right.$ a $\left.40^{\circ} \mathrm{C}\right)$ (GARCIA; JACOBI; RIBEIRO, 2007), sob luz, indicam adaptação destas espécies as áreas sujeitas a altas radiações solares e grandes flutuações circadianas de temperatura, revelando a capacidade que sementes dessas espécies para tolerar e germinar sob intensas variaçôes diárias de temperatura do substrato (GARCIA; DINIZ, 2003; GARCIA; JACOBI; RIBEIRO, 2007; MENEZES; GIULIETTI, 1986).

Em se tratando do índice de velocidade de germinação, para todas as temperaturas analisadas, os melhores resultados foram obtidos na presença de luz, exceto para a alternância de temperatura (20-30 $\left.{ }^{\circ} \mathrm{C}\right)$ a qual náo apresentou diferença estatística (Tabela 3). Na presença de luz o melhor índice de velocidade de germinaçáo foi obtido nas temperaturas de 25 e $30^{\circ} \mathrm{C}(1,75$ e 1,86 respectivamente). Já na ausência de luz, a temperatura de $30^{\circ} \mathrm{C}$ apresentou o melhor índice $(1,66)$, diferindo estatisticamente apenas das temperaturas de 20 e 20-30 ${ }^{\circ} \mathrm{C}$ (Tabela 3).
Tabela 3 - Médias obtidas para índice de velocidade de germinação (IVG) em sementes de Barbacenia paranaensis L. B. Sm., na presença (P) e ausência (A) de luz, Curitiba-PR, 2014.

\begin{tabular}{cccccc}
\hline \multicolumn{6}{c}{ Temperatura } \\
\hline Luz & $20^{\circ} \mathrm{C}$ & $25^{\circ} \mathrm{C}$ & $30^{\circ} \mathrm{C}$ & $20-30^{\circ} \mathrm{C}$ & Média \\
\hline $\mathrm{P}$ & $1,09 \mathrm{aB}$ & $1,75 \mathrm{aA}$ & $1,86 \mathrm{aA}$ & $1,14 \mathrm{aB}$ & $1,46 \mathrm{a}$ \\
$\mathrm{A}$ & $0,74 \mathrm{bC}$ & $1,40 \mathrm{bAB}$ & $1,66 \mathrm{bA}$ & $1,21 \mathrm{aB}$ & $1,25 \mathrm{~b}$ \\
\hline Média & $0,92 \mathrm{C}$ & $1,58 \mathrm{~A}$ & $1,76 \mathrm{~A}$ & $1,18 \mathrm{~B}$ & \\
\hline
\end{tabular}

Médias seguidas de mesma letra minúscula na coluna e maiúscula na linha não diferem estatisticamente entre si pelo teste de Tukey ao nível de $5 \%$ de significância.

Ao comparar os resultados da primeira contagem de germinação com os da germinação (Tabelas 1 e 2), nota-se que a temperatura afeta tanto a capacidade como a velocidade de germinação. As sementes possuem a capacidade de germinar dentro de uma determinada faixa de temperatura, porém esta influência no tempo necessário para se obter a porcentagem máxima de germinação (BEWLEY; BLACK, 1994). De acordo com os resultados apresentados, nota-se que temperaturas elevadas aumentam a velocidade de germinaçấo, enquanto temperaturas mais baixas reduzem-na e alteram a uniformidade de emergência da raiz primária (CARVALHO; NAKAGAWA, 2000).

De modo geral, pôde-se observar que as sementes de $B$. paranaensis responderam mais rapidamente ao processo germinativo nas temperaturas de $25^{\circ} \mathrm{C}$ e $30^{\circ} \mathrm{C}$, na presença de luz (Tabela 1 ); foram constatadas altas porcentagens de geminaçáo, acima de $80 \%$, independente da condiçâoo (temperatura e luz) testadas (Tabela 2), e na presença de luz a velocidade de germinaçáo foi maior, exceto quando se utilizou temperatura alternada (Tabela 3). Tais informaçóes sâo importantes para subsidiar testes de germinaçấo com a espécie e inferir sobre seu comportamento germinativo em condiçóes naturais, possibilitando a compreensão de caracteres relativos à sua ecologia. Segundo Cheib (2009), a capacidade de determinar o momento ideal para a germinação das sementes é de suma importância, visto que ele interfere no aumento da probabilidade de sucesso da germinaçáo, sendo o tempo necessário para que a semente germine um dos fatores que determinam este momento.

\section{CONCLUSÃo}

A faixa de temperatura ótima para a germinação das sementes de Barbacenia paranaensis é de $25^{\circ} \mathrm{C}$ e $30^{\circ} \mathrm{C}$. A primeira contagem de germinação pode ser 
realizada em aproximadamente 11 dias transcorridos do início do teste, encerrando-se com a contagem final de germinação após 24 dias.

\section{REFERÊNCIAS}

BASKIN, C. C.; BASKIN, J. M. Germination ecophysiology of herbaceous plant species in a temperate region. American Journal of Botany, St. Louis, v. 7, n. 2, p. 286-305, 1988.

BEWLEY, J.D.; BLACK, M. Seeds: Physiology of development and germination. 2nd. ed. New York: Plenum Press, 1994. 445p.

BRASIL. Ministério da Agricultura, Pecuária e Abastecimento. Secretaria de Defesa Agropecuária. Regras para análise de sementes. Brasília, MAPA, 2009. 395p.

CARVALHO, N. M.; NAKAGAWA, J. Sementes: ciência, tecnologia e produção. 4. ed. Jaboticabal: FUNEP, 2000. 588p.

CHEIB, A. L. Ecologia da germinaçáo e potencial para formaçáo de banco de sementes de espécies de Athrocereus A. Berger (Cactaceae) endêmicas dos campos rupestres de Minas Gerais, Brasil. 2009. 31f. Dissertação (Mestrado em Biologia Vegetal) - Universidade Federal de Minas Gerais, 2009.

GARCIA, Q. S.; DINIZ, I. S. S. Comportamento germinativo de três espécies de Velloziaceae dos campos rupestres de Minas Gerais. Acta Botanica Brasilica, Feira de Santana, v. 17, p. 487-494, 2003. Disponível em: $<$ http://www.scielo.br/scielo.php?script=sci_arttext\&pi$\mathrm{d}=$ S0102-33062003000400001 $>$. Acesso em: 10 ago. 2015. doi: 10.1590/S0102-33062003000400001.

GARCIA, Q. S.; JACOBI, C. M.; RIBEIRO, B. A. Resposta germinativa de duas espécies de Vellozia (Velloziaceae) dos campos rupestres de Minas Gerais, Brasil. Acta Botanica Brasilica, Feira de Santana, v. 21, n. 2, p. 451-456, 2007. Disponível em: <http://www.scielo.br/scielo.php?script $=$ sci_arttext $\&$ pid $=S 0102-33062007000200018>$. Acesso em: 10 ago. 2015. doi: 10.1590/S010233062007000200018 .

GHERSA, C. M.; BENETH-ARNOLD, R. L.; MARTINEZ-GHERSA, M. A. The role of fluctuating temperatures in germination and establishment of Sorghum hapelense. Regulation of germination at increasing depths. Functional Ecology, London, v. 6, p. 460-468, 1992.

GRIME, J. P. et al. A Comparative study of germination characteristics in a local flora. Journal of Ecology, London, v. 69, p. 1017-1059, 1981.
LEISHMANN, M. R. et al. The evolutionary ecology of seed size. p. 31-57. In: FENNER, M. The ecology of regeneration in plant communities. 2nd. ed. Wallingford: CABI International, 2000.

LUZ, P.M. Biologia reprodutiva e genética de populaçóes de Barbacenia paranaenses L. B. SM. (Velloziaceae), espécie endêmica e ameaçada de extinçáo no Paraná. 2014. 74f. Dissertação (Mestrado em Botânica) - Universidade Federal do Paraná, 2014.

MAGUIRE, J. D. Speed of germination-aid in selection and evaluation for seedling emergence and vigor. Crop Science, Madison, v. 2, n. 1, p. 176-177, 1962.

MARCOS-FILHO, J. Fisiologia de sementes de plantas cultivadas. Piracicaba: Fealq, 2005. 495p.

MELLO-SILVA, R. Novitates velloziacearum florae phanerogamicae Sanci Pauli. Revista Brasileira Botânica, São Paulo, v. 27, n. 3, p. 453-462, 2004. Disponível em: <http://www.scielo.br/scielo.php?pi$\mathrm{d}=S 0100-84042004000300006 \&$ script $=$ sci_art text>. Acesso em: 10 ago. 2015. doi: 10.1590/S010084042004000300006 .

MELLO-SILVA, R. Velloziaceae In: GIULETT, A. M et al. Plantas Raras do Brasil. Belo Horizonte: Conservação Internacional, 2009. p.392-398.

MELLO-SILVA, R. Velloziaceae. In: LISTA de Espécies da Flora do Brasil. Rio de Janeiro: Jardim Botânico do Rio de Janeiro, 2013. Disponível em: <http://floradobrasil.jbrj. gov.br/2012/FB000245>. Acesso em: 23 fev. 2015.

MENEZES, N. L.; GIULIETTI, A. M. Serra do Cipó Paraíso dos Botânicos. Ciência Hoje, Rio de Janeiro, v. 25, n. 5, p. 38-44, 1986.

MOLES, A. T.; ACKERLY, D. D.; WEBB, C. O.; TWEDDLE, J. C.; DICKIE, J. B.; WESTOBY, M. A brief history of seed size. Science, Washington, v. 307, p. 576-580, 2005.

SAZIMA, M. Biologia floral de espécies de Velloziaceae na Serra do Cipó, Minas Gerais. 1978. 188f. Tese (Doutorado) - Universidade de São Paulo, 1978.

SMITH, H. Light quality and germination: ecological implications. In: HEYDECHER, W. Seed ecology. London: Buttrworth, 1975. p.131-219.

SOARES, L. A.; GARCIA, Q. S. Germinação de quatro espécies de Velloziaceae ocorrentes em diferentes ambientes. Anais... Caxambu: VIII Congresso de Ecologia do Brasil, 2007. 